\title{
Evolutionary Game Analysis and Simulations for Intra-Village Conflict of Collective Land Expropriation
}

\author{
Haowen Wang ${ }^{1}$, Qiuxiang $\mathrm{Li}^{2}$, Haijun $\mathrm{Bao}^{2}$, Yi Peng ${ }^{2}$ * \\ ${ }^{1}$ School of Business Administration, Zhejiang University of Finance \& Economics, Hangzhou 310018, China \\ ${ }^{2}$ School of Public Administration, Zhejiang University of Finance \& Economics, Hangzhou 310018, China
}

\section{集体土地征收的村内冲突的演化博弯分析及动态仿真}

\author{
王浩文 ${ }^{1}$, 李秋香 ${ }^{2}$, 鲍海君 $^{2}$, 彭毅 ${ }^{2 *}$ \\ ${ }^{1}$ 浙江财经大学工商管理学院, 浙江 杭州 310018 \\ ${ }^{2}$ 浙江财经大学公共管理学院, 浙江 杭州 310018
}

\begin{abstract}
With rapid urbanization, the social risk caused by collective land expropriation has been increasing. Land conflict rather than the farmers' burden has been the first important issue affecting social security in rural areas. The existing studies on land conflict pay few attentions to intra-village conflict of collective land expropriation. The behavior logic and evolution rule of farmers and village committee remains unknown during the conflict of collective land expropriation. Therefore, the governmental measures lack solid basis to solve such conflicts. This study conducts evolutionary game analysis to find the evolutionary stable strategy of farmers and village committee during conflicts based on the assumption of bounded rationality. Through NetLogo platform, multi-agent based simulation is conducted to validate the results of evolutionary game analysis. This study provides theoretical references for solving intra-village conflicts during collective land expropriation.
\end{abstract}

*通讯作者: 彭毅, 杭州市浙江财经大学公共管理 学院, Email:pengyihz@zufe.edu.cn
Keywords: collective land expropriation; intra-village conflict; social risk; evolutionary game analysis; multi-agent-modeling; NetLogo platform

\section{摘要}

随着城镇化快速推进, 集体土地征收引发的社会 风险不断增大, 已取代农民负担问题成为当前影响农 村社会稳定和发展的首要问题。现有的土地冲突研究 缺乏对集体土地征收村内冲突的专门分析, 冲突过程 中被征地农民与村委会的行为逻辑及其变化规律不明, 导致出台的政策缺乏微观执行基础, 治理绩效不佳, 函需新的研究视角与方法。本研究在有限理性假设基 础上, 建立演化博亦模型, 识别被征地农民与村委会 的演化稳定策略。应用多主体建模仿真, 基于 NetLogo 多主体建模仿真平台, 分析不同收益值情况下集体土 地征收博亦达到的演化均衡状态, 为有效规避集体土 地征收村内冲突, 提供一定理论指导。

关键词: 集体土地征收; 村内冲突; 社会风险; 演 化博亦; 多主体建模; NetLogo 平台

\section{1. 引言}

随着城市化的快速推进, 大量集体土地被征收转用, 土地非农化为中国工业化和城市化的快速发展提供了 


\section{Risk Analysis and Crisis Response in Big Data Era (RAC-16)}

大规模的非农建设用地保障, 在一定程度上也成为解 释中国经济高速增长的一个重要因素[1-3]。中国现行 的征收制度和土地出让制度存在明显的“双轨”特征 [4], 这一特征使得同一宗地的征收和出让价格相差悬殊 [5], 加之“强统治、弱治理”畸形管理模式下政府主导的快 速城市化产生的空间转型与渐进式改革推进的社会制 度转型难以匹配[6], 在城乡结合部产生了大量的以利 益诉求为主要特征的征收拆迁冲突。研究表明因土地 问题尤其是征收拆迁引发的社会矛盾不断激化，已取 代农民负担问题成为当前影响农村社会稳定和发展的 首要问题[7]。在村集体内, 存在着有一定利益冲突的 村委会与被征地农民, 如果利益未得到较好地协调, 常爆发一定的村内冲突, 影响社会基层的稳定。在对 待集体土地征收问题上, 村委会的双重身份使其成为 一个有相对独立的利益群体。在负责土地补偿费的分 配时, 有为追求其利益最大化, 而借农地产权界定不 清之便擢取农民个体财产权利之嫌[8]。由于乡镇人民 政府管理职责的缺失、村民自治制度不够健全，村务 运行缺乏监督等原因, 常常造成村民委员会的权力越 位, 村委会从集体土地的管理者变成了利用集体土地 逐利的“谋利者”。而被征地之后, 农民作为土地的被 剥夺者, 失去了赖以生存的土地, 并丧失了土地附属 相关权益, 如土地收益权、土地处置权等[9], 同时打 破了他们对熟悉环境的依赖, 他们的社会关系也会受 到影响或打破, 生存成本增加。而对于征地收益农民 受其自身视野的局限往往不能全面观察和考虑, 而对 于失地引起的成本却看得很清楚, 于是为了减少征地 所造成的利益损失, 在对征收补偿标准不满意时, 他 们往往想方设法寻找多种途径与村级组织和基层政权 相抗衡。在此过程中被征地农民往往不自觉地产生了 一种抵触情绪, 滋生了冲突。

现有的土地冲突研究, 基于利益相关者博竕视角 [10-11]，对中央政府、地方政府、村集体组织、被征 地农民和开发商等利益主体的博亦策略影响因素进行 了相关定性研究 [12]。在定性研究的基础上构建各类主 体行为的博亦模型并进行定量分析, 探索各博亦主体 的利益关系以及由此产生的行为选择和能否取得多赢 可能性等问题。同时, 多类型的博亦分析方法如动态 博亦分析、比较静态博亦分析、演化博亦分析等都用 于对征地拆迁冲突、补偿以及制度改革等问题的研究 中[14-15]。对中国征收拆迁冲突个案研究表明, 地方 政府在以工业化导向的经济发展目标的诱导下，不断 通过征收拆迁获取租金最大化, 其后果不仅引起农民 的强烈不满和大量抗争活动, 而且还威胁到中央政府
的粮食安全目标以及社会的公正和稳定性[16]。因此, 土地冲突的演化过程也是国家、地方政府以及农民之 间利益关系进行重新界定和相互妥协的过程 [17]。

既有研究成果从理论与方法上为揭示冲突原因和 探索治理策略等奠定了一定的基础, 但其局限性也比 较明显, 可归为以下两个方面: 一是缺乏对集体土地 征收村内冲突的专门研究, 尽管新闻媒体对该现象作 了大量报道, 学术界对此问题的专门研究则比较缺乏。 二是现有研究缺乏从心理学和行为科学等角度来解释 冲突过程中参与者的行为逻辑及其变化规律。这些局 限的存在使得集体土地上征收拆迁冲突的发生机理与 演化规律尚不明确, 出台的政策缺乏微观执行基础, 往往隔靴拴痒, 治理绩效不佳, 函需新的研究视角与 方法。

近年来基于多主体(Agent-Based-Method, ABM)的 建模与仿真方法, 适用于冲突研究中分析政策利益相 关者的行为与互动, 开启了社会科学仿真的新时代 [18-19]。基于多主体的建模方法采用自下而上的研究 思路, 通过在微观层次上构造系统中的个体行为, 观 察其行为决策与交互机制来研究系统的整体涌现特性, 是一种行之有效的建模方法。基于此背景, 本文首先 在有限理性假设基础上运用演化博亦论建立冲突博亦 模型, 并采用多主体建模工具 NetLogo 进行多情景仿 真, 验证相关理论研究结论, 为有效规避集体土地征 收村内冲突, 提供一定理论指导。

\section{2. 集体土地征收的村内冲突的演化博弯模型}

\section{1. 模型基本假设}

被征地农民与村委会在集体土地征收中的博亦为非对 称博竕, 博峦双方选择策略的过程基于有限理性和不 确定性, 是一个随时间变化的动态博亦过程。为了更 好地进行研究分析, 先对该演化博峦模型作以下基本 假设:

（1）随机配对的两两博亦。尽管被征地农民和村 委会两个群体中的个体在进行决策时面对的是对方群 体的所有个体, 但该模型假设博亦是在两类群体中的 个体之间随机配对两两反复进行的。

（2）有限理性的经济人。被征地农民和村委会都 是有限理性的经济人, 这意味着博弯双方在进行博亦 策略选择的时候, 无法在一开始就能够选择到最优策 略, 而是经过不断试错和不断学习后才找到最优策略。 双方采取最优策略的原则都是从自身需求和实际情况 
Risk Analysis and Crisis Response in Big Data Era (RAC-16)

出发追求自身利益的最大化。同时, 策略调整的速率 用生物进化动态方程即复制动态方程表示。

(3) 非对称演化博亦。虽然村委会成员在征地中 也是被征收对象，但其同时具备代表地方政府管理村 内事务的“代理人”角色, 因此被征地农民与村委会双 方是不相似的, 所获得收益以及所花费成本等都不尽 相同。被征地农民的博亦策略为顺从和不顺从，顺从 意味着被征地农民配合村委会的征地村内工作，不顺 从意味着被征地农民抵制村委会的征地村内工作。村 委会的博亦策略为合规操作和违规操作, 合规操作意 味着村委会按照相关法律和规章制度进行征收的村内 协调和管理等工作，违规操作则意味着村委会的权力 越位或者借农地产权界定不清之便搇取农民个体财产 权利的情况，侵犯了被征地农民的集体土地权益。

\section{2. 被征地村民与村委会的博弃策略与收益}

基于上述模型假设，建立被征地农民与村委会的非对 称演化博弯模型。为了简化分析, 设被征地农民与村 委会在征地拆迁中获得的收益总额为 $R$, 其中村委会获 得的收益值为 $\alpha \mathrm{R}$, 相应的被征地农民获得的收益值为 $(1-\alpha) R$, 其中 $0 \leq \alpha \leq 1$; 由于村委会中所有博弯个 体也都是被征收对象, 因此被征地农民配合村委会工 作时, 村委会同被征地农民所付出的征地拆迁执行成 本相同均为C。而当被征地农民采取不顺从策略时, 村 委会和被征地农民的执行成本都将发生变化分别为 $\mathrm{f}_{1} \mathrm{C}$ 和 $\mathrm{f}_{2} \mathrm{C}$, 同时, 村委会违规操作的风险因子为 $\mathrm{f}_{3}$, 即 其违规操作的执行成本为 $\mathrm{f}_{3} \mathrm{C}$ 。

村委会的策略集为 $S_{x}$ (合规操作, 违规操作), 被 征地农民的策略集为 $\mathrm{S}_{\mathrm{y}}$ (顺从, 不顺从), 用

$\left(U_{1 s} 、 U_{1 \mathrm{t}} 、 U_{2 \mathrm{~s}} 、 \mathrm{U}_{2 \mathrm{t}}\right)$ 分别表示博弯双方在不同策略 下的平均收益。该模型共有四种博弯结果: (1)村内和 谐 (顺从, 合规操作), 博弯双方的支付函数分别为 $\alpha_{1} R-C$ 和 $\left(1-\alpha_{1}\right) R-C$ 。此时被征地农民依照规范参 与村民代表大会并配合村委会的决议完成征地工作, 村委会则代表村民利益在地方政府与村民之间进行沟 通协商, 向村民及时完整地通报征收工作的进展情况, 依照规范召开村民代表大会形成决议并依法管理村民 的征地补偿等。以 $\alpha_{1}$ 代表村委会此时在征地拆迁总收 益中所占的比例, 从而被征地农民此时的收益比例为 $\left(1-\alpha_{1}\right)$ 。而因为双方整个过程都较为顺利和谐, 从而 不会花费多余的成本, 同时村委会成员也属于被拆迁 农民，因此设定不论村委会还是被征地农民在此种博 亦结果下的成本均为村民征收的执行成本C。(2)村内抵 制 (不顺从, 合规操作), 被征地农民可能存在认为征
地补偿款以及回迁地选址不合理或对村委会存在不信 任等情况, 从而即使村委会依法合规的进行关于征地 的村内协商调解和决议等工作, 但被征地农民出于上 述原因仍会选择不顺从策略。因此博交双方的支付函 数分别为 $\alpha_{2} R-\left(1+f_{1}\right) C$ 和 $\left(1-\alpha_{2}\right) R-\left(1+f_{2}\right) C$, 以 $\alpha_{2}$ 代表村委会此时在征地总收益中所占的比例, 从而 被征地农民此时的收益比例为 $\left(1-\alpha_{2}\right)$, 同时, 由于此 时双方的成本相较于第(1)类博亦情况都有所改变, 从 而以 $\mathrm{f}_{1} \mathrm{C}$ 表示此时村委会的执行成本, 以 $\mathrm{f}_{2} \mathrm{C}$ 表示村民的 执行成本。若村民不同意征收决议从而没有得到相应 的征地收益, 而此时村委会成员则带头接受征收, 则 将会出现此博亦结果的极端情况即 $\alpha_{2}=1,1-\alpha_{2}=$ 0 的情况。(3)村内侵犯 (顺从, 违规操作), 博亦双方 的支付函数分别为 $\alpha_{3} R-\left(1+f_{3}\right) C$ 和 $\left(1-\alpha_{3}\right) R-C$ 。 此时被征地农民妥协于村委会诸如征地村内协商程序 不规范, 村委会成员以权谋私, 征地补偿款管理和分 配存在腐败以及屏蔽群众的知情权和参与权等违法违 规的操作行为, 选择默许或随大流的顺从策略。以 $\alpha_{3}$ 代 表村委会此时在征地总收益中所占的比例, 从而被征 地农民此时的收益比例为 $\left(1-\alpha_{3}\right)$, 同时村委会因违规 操作而付出一定的风险执行成本即为 $\mathrm{f}_{3} \mathrm{C}$ 。(4)村内冲突 (不顺从, 违规操作), 此时被征地农民不再默许和顺 从于村委会在征地问题上的各种违法违规操作行为, 从而将采取如静坐示威、围堵交通、暴力冲击以及越 级上访等较为激烈的抵制和斗争策略以对抗村委会在 征地问题上的违法违规操作行为, 双方将爆发征地的 村内冲突。此时博亦双方的支付函数分别为

$\alpha_{4} R-\left(1+f_{1}+f_{3}\right) C$ 和 $\left(1-\alpha_{4}\right) R-\left(1+f_{2}\right) C$, 以 $\alpha_{4}$ 代 表村委会此时在征地总收益中所占的比例, 从而被征 地农民此时的收益比例为 $\left(1-\alpha_{4}\right)$ 。双方的演化博峦的 支付矩阵如下 (表 1) 所示。

\section{3. 演化博弯分析与稳定策略}

假设被征地农民采取顺从的比例为 $\mathrm{x}$, 则其采取不顺从 的比例为 $1-x$ 。村委会合规操作的概率比例为 $y$, 则 其违规操作的概率比例为 $1-\mathrm{y}$ 。由被征地农民同村委 会征地的支付矩阵可得 被征地农民采取顺从策略的平均收益为 $\mathrm{U}_{1 \mathrm{~s}}$ : $\mathrm{U}_{1 \mathrm{~s}}=\mathrm{y}\left[\left(1-\alpha_{1}\right) \mathrm{R}-\mathrm{C}\right]+(1-\mathrm{y})\left[\left(1-\alpha_{3}\right) \mathrm{R}-\mathrm{C}\right]$ 被征地农民采取不顺从策略的平均收益为 $\mathrm{U}_{1 \mathrm{t}}$ : $\mathrm{U}_{1 \mathrm{t}}=\mathrm{y}\left[\left(1-\alpha_{2}\right) \mathrm{R}-\left(1+\mathrm{f}_{2}\right) \mathrm{C}\right]+(1-\mathrm{y})\left[\left(1-\alpha_{4}\right) \mathrm{R}\right.$ $\left.-\left(1+\mathrm{f}_{2}\right) \mathrm{C}\right]$

被征地农民的平均收益为 $\overline{\mathrm{U}_{1}}$ : 
Risk Analysis and Crisis Response in Big Data Era (RAC-16)

表 1 集体土地征收时被征地农民与村委会博弯的支付矩阵

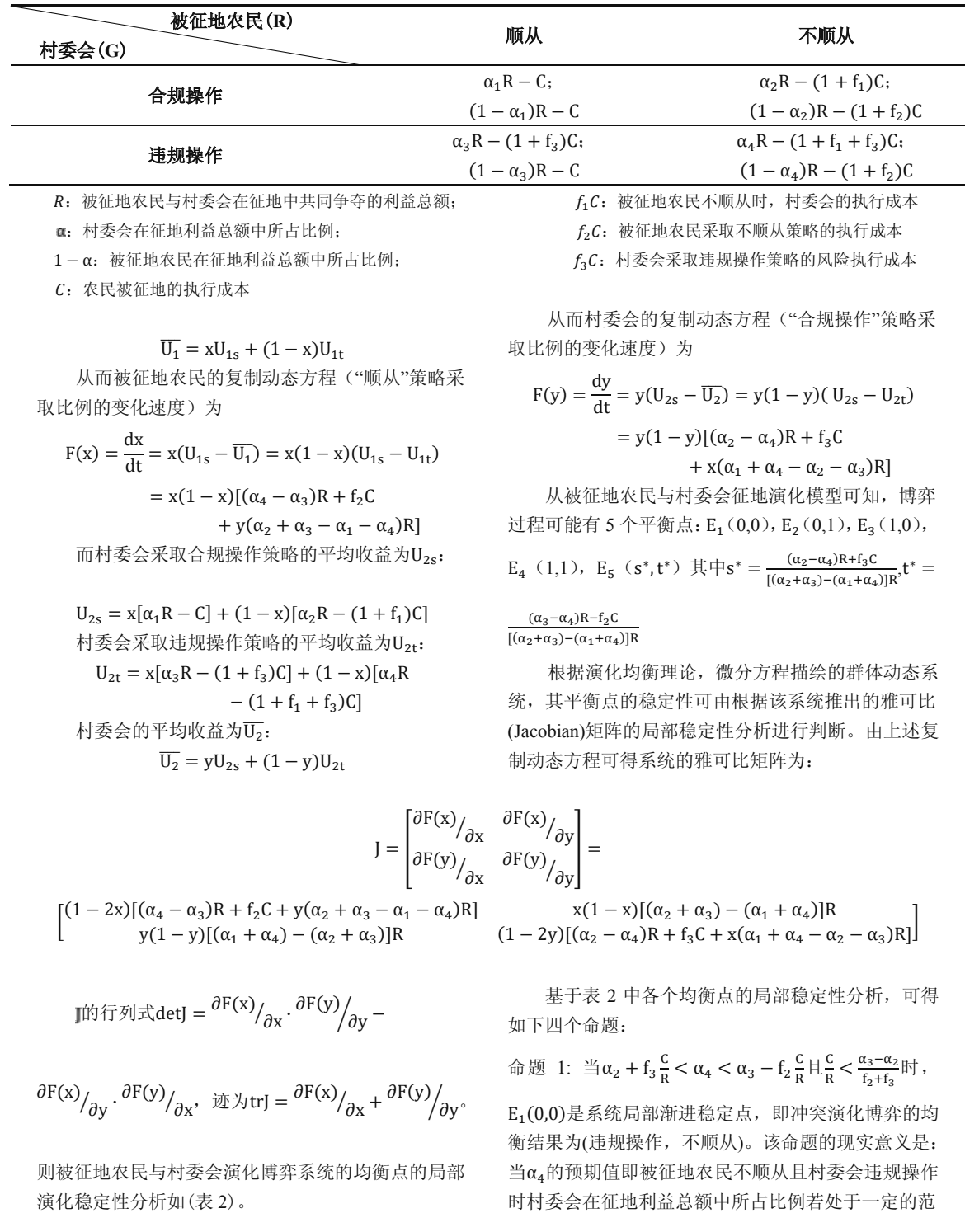


Risk Analysis and Crisis Response in Big Data Era (RAC-16)

表 2 被征地农民与地方政府演化博弯系统的均衡点的局部演化稳定性分析

\begin{tabular}{ccc}
\hline 平衡点 & J的行列式det & J的迹trJ \\
\hline $\mathrm{E}_{1}(0,0)$ & {$\left[\left(\alpha_{4}-\alpha_{3}\right) \mathrm{R}+\mathrm{f}_{2} \mathrm{C}\right] \cdot\left[\left(\alpha_{2}-\alpha_{4}\right) \mathrm{R}+\mathrm{f}_{3} \mathrm{C}\right]$} & $\left(\alpha_{2}-\alpha_{3}\right) \mathrm{R}+\left(\mathrm{f}_{2}+\mathrm{f}_{3}\right) \mathrm{C}$ \\
$\mathrm{E}_{2}(0,1)$ & {$\left[\left(\alpha_{2}-\alpha_{1}\right) \mathrm{R}+\mathrm{f}_{2} \mathrm{C}\right] \cdot\left[\left(\alpha_{4}-\alpha_{2}\right) \mathrm{R}-\mathrm{f}_{3} \mathrm{C}\right]$} & $\left(\alpha_{4}-\alpha_{1}\right) \mathrm{R}+\left(\mathrm{f}_{2}-\mathrm{f}_{3}\right) \mathrm{C}$ \\
$\mathrm{E}_{3}(1,0)$ & {$\left[\left(\alpha_{3}-\alpha_{4}\right) \mathrm{R}-\mathrm{f}_{2} \mathrm{C}\right] \cdot\left[\left(\alpha_{1}-\alpha_{3}\right) \mathrm{R}+\mathrm{f}_{3} \mathrm{C}\right]$} & $\left(\alpha_{1}-\alpha_{4}\right) \mathrm{R}+\left(\mathrm{f}_{3}-\mathrm{f}_{2}\right) \mathrm{C}$ \\
$\mathrm{E}_{4}(1,1)$ & {$\left[\left(\alpha_{2}-\alpha_{1}\right) \mathrm{R}+\mathrm{f}_{2} \mathrm{C}\right] \cdot\left[\left(\alpha_{1}-\alpha_{3}\right) \mathrm{R}+\mathrm{f}_{3} \mathrm{C}\right]$} & $\left(\alpha_{3}-\alpha_{2}\right) \mathrm{R}-\left(\mathrm{f}_{2}+\mathrm{f}_{3}\right) \mathrm{C}$ \\
$\mathrm{E}_{5}\left(\mathrm{~s}^{*}, \mathrm{t}^{*}\right)$ & $\mathrm{M}_{1}$ & 0 \\
\hline
\end{tabular}

围内, 且村民的成本收入比小于某一可推算值时, 被 征地农民和村委会倾向的策略选择是: 不顺从与违规 操作, 即此时双方将发生有关集体土地征收的村内冲 突。

命题 2: 当 $\alpha_{4}-\mathrm{f}_{3} \frac{\mathrm{C}}{\mathrm{R}}<\alpha_{2}<\alpha_{1}-\mathrm{f}_{2} \frac{\mathrm{C}}{\mathrm{R}}$ 且 $\frac{\mathrm{C}}{\mathrm{R}}>\frac{\alpha_{4}-\alpha_{1}}{\mathrm{f}_{3}-\mathrm{f}_{2}}$

时, $\mathrm{E}_{2}(1,0)$ 是系统局部渐进稳定点, 即冲突演化博亚 的均衡结果为 (合规操作, 不顺从)。该命题的现实意 义是：当 $\alpha_{2}$ 的预期值，即被征地农民不顺从而村委会 合规操作时, 村委会在征地利益总额中所占比例若处 于一定的范围内, 且村民的成本收入比大于某一可推 算值时。 $\alpha_{1}$ 和 $\alpha_{4}$ 的值越大，或者村民的成本收入比越 小，村委会合规操作的预期收益比例区间越大，那么 村委会将倾向于选择合规操作策略。 $\alpha_{1}$ 和 $\alpha_{4}$ 的值越小, 或者村民的成本收入比越大, 被征地农民不顺从的预 期收益比例区间则越大，那么被征地农民都将倾向于 逐步选择不顺从策略, 这符合双方此时策略对立参数 零和的情况, 即此时双方将发生有关集体土地征收的 村内抵制的情况。

$$
\text { 命题 3: 当 } \alpha_{1}+\mathrm{f}_{3} \frac{\mathrm{C}}{\mathrm{R}}<\alpha_{3}<\alpha_{4}+\mathrm{f}_{2} \frac{\mathrm{C}}{\mathrm{R}} \text { 且 } \frac{\mathrm{C}}{\mathrm{R}}<\frac{\alpha_{4}-\alpha_{1}}{\mathrm{f}_{3}-\mathrm{f}_{2}}
$$

时, $\mathrm{E}_{3}(0,1)$ 是系统局部渐进稳定点, 即冲突演化博弯 的均衡结果为 (违规操作, 顺从) 。该命题的现实意义 是: 当 $\alpha_{3}$ 的预期值, 即被征地农民顺从而村委会违规 操作时, 村委会在征地利益总额中所占比例若处于一 定的范围内, 且村民的成本收入比小于某一可推算值 时。 $\alpha_{1}$ 和 $\alpha_{4}$ 的值越大, 或者村民的成本收入比越大, 村委会违规操作的预期收益比例区间越大，那么村委 会将倾向于选择违规操作策略。 $\alpha_{1}$ 和 $\alpha_{4}$ 的值越小, 或 者村民的成本收入比越小，被征地农民顺从的预期收 益比例区间则越大，那么被征地农民都将倾向于逐步 选择顺从策略。这符合双方此时策略对立参数零和的 情况, 从而此时双方将发生有关集体土地征收的村内 侵权的情况。

$$
\text { 命题 4: 当 } \alpha_{3}-\mathrm{f}_{3} \frac{\mathrm{C}}{\mathrm{R}}<\alpha_{1}<\alpha_{2}+\mathrm{f}_{2} \frac{\mathrm{C}}{\mathrm{R}} \text { 且 } \frac{\mathrm{C}}{\mathrm{R}}>\frac{\alpha_{3}-\alpha_{2}}{\mathrm{f}_{2}+\mathrm{f}_{3}}
$$

时, $\mathrm{E}_{4}(1,1)$ 是系统局部渐进稳定点, 即冲突演化博亦 的均衡结果为 (合规操作, 顺从)。该命题的现实意义 是: 当 $\alpha_{1}$ 的预期值, 即被征地农民顺从且村委会合规 操作时, 村委会在征地利益总额中所占比例若处于一 定的范围内, 且村民的成本收入比大于某一可推算值 时, 被征地农民和村委会倾向的策略选择是: 顺从与 合规操作, 即此时双方关于集体土地征收为村内和谐 状态。

为了进一步证明以上结论, 下面将采用基于多主 体仿真方法进行数值模拟。

\section{3. 数值仿真分析}

\section{1. 基于多主体方法(ABM)的建模仿真平台}

目前常用的多主体仿真平台主要有 Swarm、 Repast、NetLogo 等, 其中 NetLogo 仿真平台在建模过 程中能控制多个个体, 适用于自然和社会系统中各类 复杂对象随时间变化而变化的复杂系统, 且语言简单、 灵活, 界面友好。因此, 本文运用 NetLogo 仿真工具 来研究集体土地征收村内冲突的行为演化, 其操作步 骤包括:

（1）基于现实抽象出一系列假设, 确定系统中的 Agent 和环境;

（2）根据假设建立概念模型, 确定 Agent 的属性 值、设计行为规则和交互算法;

（3）进行计算机仿真实验, 分析宏观涌现动态和 结果。

\section{2. 仿真参数设置}

本文着重研究集体土地征收过程中村委会与被征 地居民之间的利益博亦及行为策略演化机理, 因此在 模型中假设有三类主体: 村委会、被征地农民和现实 环境。现实环境是一个虚拟主体, 不参与仿真模型的 模拟, 主要生成供主体活动的空间、记录其他主体的 属性变化及数量。在该模型中, 假设系统环境为一正 方形区域, 环境中初始有村委会 Agent 和被征地农民 Agent 随机分布, 并在每个循环周期内随机移动 (如图 1 所示)。 
Risk Analysis and Crisis Response in Big Data Era (RAC-16)
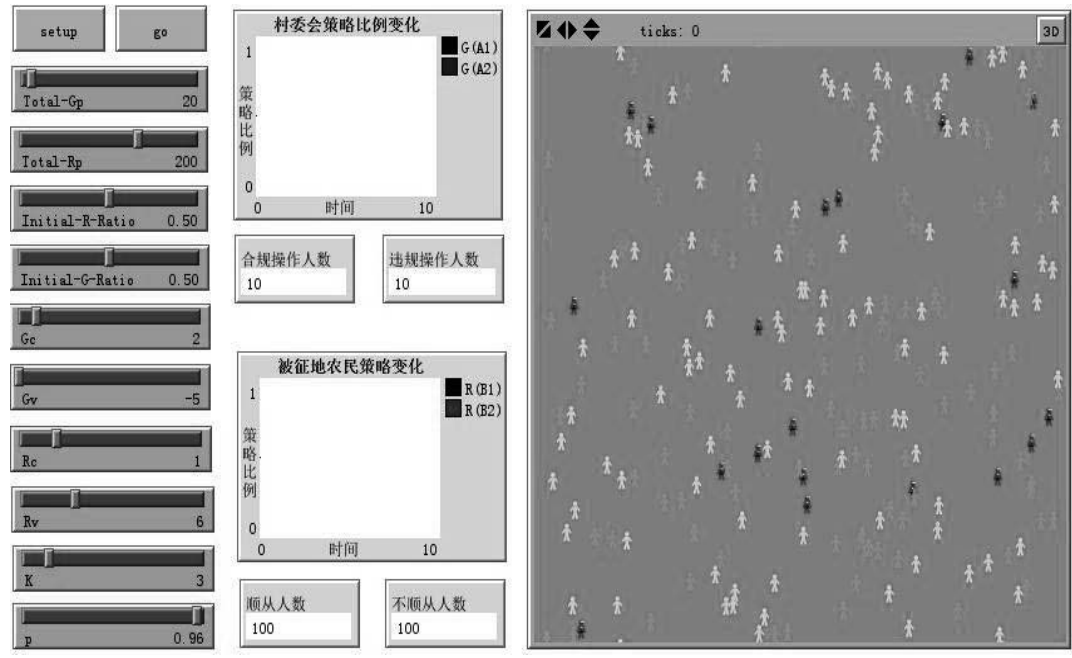

图 1 村委会群体与被征地农民群体博弯仿真示意图

（1）初始条件: 村委会群体和被征地农民群体数 目比例为 20:200, 同一类主体的两种策略初始比均为 $1: 1$;

（2）仿真周期：每个仿真周期对应现实环境中村 委会和被征地农民的一轮博亦时间一个月，每次试验 运行总时长为 $T$ 周期 $(T<=80)$, 则整个试验相当于模拟 不超过 7 年的博竕过程;

(3) 行为规则: 个体策略在演化过程中可以学习和 模仿其他个体的行为;

(4) 终止条件: 系统中群体策略比例不再随时间变 化, 即博弯达到稳定均衡解。

\section{3. 仿真实验}

(1) 验证命题 1: 模拟参数取为 $\alpha_{1}=0.5, \alpha_{2}=0.1, \alpha_{3}=0.8$, $\alpha_{4}=0.5, \mathrm{f}_{1}=0.5, \mathrm{f}_{2}=0.5, \mathrm{f}_{3}=0.5, \mathrm{C}=1, \mathrm{R}=10$, 满足命题 1 条 件, 则系统稳定策略解为 $\mathrm{E}_{1}(0,0)$, 即冲突演化博亦的 均衡结果为 (违规操作, 不顺从)。

图 2(a)中的仿真结果表明, 村委会群体初始合规 征地和违规征地比例均为 0.5 。村委会群体在与不顺从 被征地人利益博竕的过程中, 当其采取违规操作策略 收益比例大于合规操作收益 $\left(\alpha_{2} R-\left(1+f_{1}\right) C<\alpha_{4} R-\right.$ $\left.\left(1+\mathrm{f}_{1}+\mathrm{f}_{3}\right) \mathrm{C}\right)$ 时, 初始一部分合规操作的村委会群体 在巨大利益诱惑下逐渐转变策略为违规操作策略。相

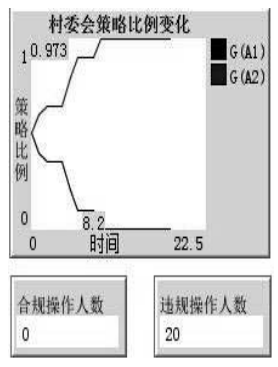

(a)

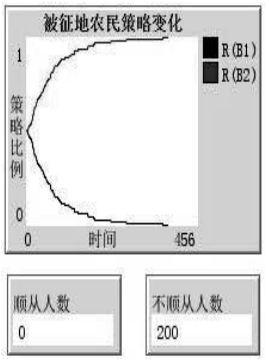

(b)

图 2 当 $\alpha_{2}+\mathrm{f}_{3} \frac{\mathrm{C}}{\mathrm{R}}<\alpha_{4}<\alpha_{3}-\mathrm{f}_{2} \frac{\mathrm{C}}{\mathrm{R}}$ 且 $\frac{\mathrm{C}}{\mathrm{R}}<\frac{\alpha_{3}-\alpha_{2}}{\mathrm{f}_{2}+\mathrm{f}_{3}}$ 时, 冲突演化博 栾的均衡结果为 (违规操作, 不顺从)

比而言, 图 2(b)中的仿真结果表明, 在村委会违规操 作压制下, 当被征地农民采取不顺从收益大于顺从收 益. $\left(\left(1-\alpha_{3}\right) R-C<\left(1-\alpha_{4}\right) R-\left(1+f_{2}\right) C\right)$ 时, 被征地农 民倾向采取抵抗策略, 随着维权意识的提高, 被征地 农民在跟村委会进行多轮博亦后, 为了维护自身的长 远利益, 其策略最终由顺从转为全部采取不顺从策略。 在实际征地项目中, 当村委会违规操作征地时, 往往 会引发被征地农民的强力抵抗, 极易爆发冲突, 影响 社会稳定, 应当采取有效措施避免这一均衡策略出现。

(2) 验证命题 2 : 模拟参数取 $\alpha_{1}=0.8, \alpha_{2}=0.5, \alpha_{3}=0.5$, 
Risk Analysis and Crisis Response in Big Data Era (RAC-16)

$\alpha_{4}=0.5, \mathrm{f}_{1}=0.5, \mathrm{f}_{2}=0.1, \mathrm{f}_{3}=0.8, \mathrm{C}=2, \mathrm{R}=10$, 满足命题 2 条 件, 则系统稳定策略为 $\mathrm{E}_{2}(1,0)$, 即冲突演化博亦的均 衡结果为 (合规操作, 不顺从) 。

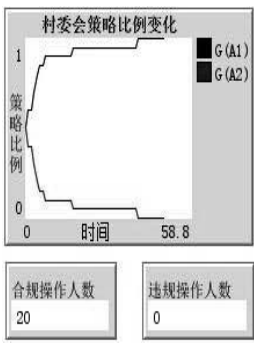

(a)

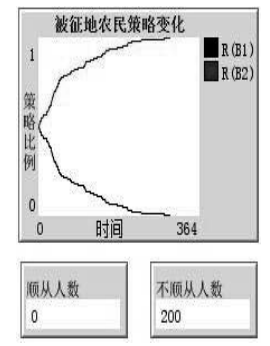

(b)
图 3 当 $\alpha_{4}-\mathrm{f}_{3} \frac{\mathrm{C}}{\mathrm{R}}<\alpha_{2}<\alpha_{1}-\mathrm{f}_{2} \frac{\mathrm{C}}{\mathrm{R}}$ 且 $\frac{\mathrm{C}}{\mathrm{R}}>\frac{\alpha_{4}-\alpha_{1}}{\mathrm{f}_{3}-\mathrm{f}_{2}}$ 时, 冲突演化博 弯的均衡结果为 (合规操作, 不顺从)

图 3 的仿真结果表明, 当提高村委会合规操作收 益 $\left(\alpha_{2} R-\left(1+f_{1}\right) C>\alpha_{4} R-\left(1+f_{1}+f_{3}\right) C\right)$ 时, 村委会群 体倾向于采取合规操作策略, 而此时被征地农民顺从 政府收益仍然小于不顺从收益 $\left(\alpha_{1} R-C<\alpha_{2} R-(1+\right.$ $\left.\mathrm{f}_{1}\right) \mathrm{C}$ )时, 选择不顺从策略的比例仍然逐渐增大, 直到 群体策略统一为不顺从。两群体在长期博亦后达到博 弯均衡策略(村委会合规操作, 农民不顺从)。在实际工 作中, 要尽量提高村委会合规操作收益, 如通过设置 村委会合规操作的相关奖励, 同时通过提高农民征地 收益、增加奖励顺从农民等举措提高被征地农民顺从 收益, 引导被征地农民策略转为顺从策略, 有效的保 证政府征地项目的顺利开展。

(3) 验证命题 3 : 模拟参数取 $\alpha_{1}=0.1, \alpha_{2}=0.5, \alpha_{3}=0.5$, $\alpha_{4}=0.6, \mathrm{f}_{1}=0.5, \mathrm{f}_{2}=0.5, \mathrm{f}_{3}=0.6, \mathrm{C}=2, \mathrm{R}=10$, 满足命题 3 条 件, 则系统稳定策略为 $\mathrm{E}_{3}(0,1)$, 即冲突演化博亦的均 衡结果为 (违规操作, 顺从)。

图 4 的仿真结果表明, 当村委会群体合规操作收益小 于违规操作收益 $\left(\alpha_{1} R-C<\alpha_{3} R-\left(1+f_{3}\right) C\right)$ 时, 被征 地农民在村委会强力压制下顺从收益仍然大于不顺从 收益 $\left(\alpha_{1} \mathrm{R}-\mathrm{C}>R-\left(1+\mathrm{f}_{1}\right) \mathrm{C}\right)$ 时, 两群体在长期博弯 后达到均衡策略 (违规操作, 顺从)。这样的均衡结果 长久下去势必会侵犯被征地农民的合作权益, 同时也 会助长村委会违规行为。因此在现实工作中, 需要适 当降低村委会的违规操作收益, 其中有效办法办法之 一即是增加对村委会违规操作的处罚力度。

(4) 验证命题 4 : 模拟参数取 $\alpha_{1}=0.5, \alpha_{2}=0.8, \alpha_{3}=0.2$, $\alpha_{4}=0.5, \mathrm{f}_{1}=0.5, \mathrm{f}_{2}=0.15, \mathrm{f}_{3}=0.15, \mathrm{C}=2, \mathrm{R}=10$, 满足命题 4
条件, 则系统稳定策略为 $\mathrm{E}_{4}(1,1)$, 即冲突演化博弯的 均衡结果为 (合规操作, 顺从) 。

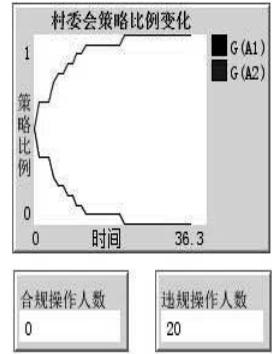

(a)

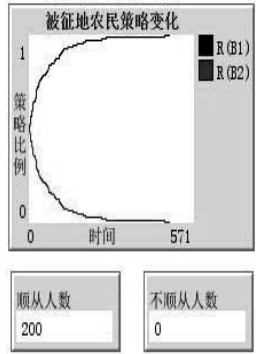

(b)
图 4 当 $\alpha_{1}+\mathrm{f}_{3} \frac{\mathrm{C}}{\mathrm{R}}<\alpha_{3}<\alpha_{4}+\mathrm{f}_{2} \frac{\mathrm{C}}{\mathrm{R}} \mathrm{H} \frac{\mathrm{C}}{\mathrm{R}}<\frac{\alpha_{4}-\alpha_{1}}{\mathrm{f}_{3}-\mathrm{f}_{2}}$ 时, 冲突演化博 亦的均衡结果为 (违规操作, 顺从)

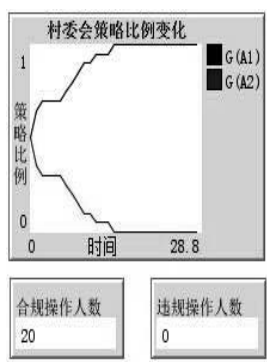

(a)

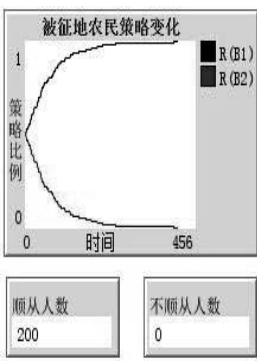

(b)
图 5 当 $\alpha_{2}+\mathrm{f}_{2} \frac{\mathrm{C}}{\mathrm{R}}<\alpha_{1}<\alpha_{3}-\mathrm{f}_{3} \frac{\mathrm{C}}{\mathrm{R}}$ 且 $\frac{\mathrm{C}}{\mathrm{R}}<\frac{\alpha_{3}-\alpha_{2}}{\mathrm{f}_{2}+\mathrm{f}_{3}}$ 时, 冲突演化 博弯的均衡结果为(顺从, 合规操作)

图 5 的仿真结果可以看出, 当村委会合规操作收 益大于违规操作效益 $\left(\alpha_{1} R-C>\alpha_{3} R-\left(1+f_{3}\right) C\right)$, 且 被拆迁人顺从收益大于不顺从收益 $\left(\alpha_{1} \mathrm{R}-\mathrm{C}>R-\right.$ $\left.\left(1+\mathrm{f}_{1}\right) \mathrm{C}\right)$ 时, 被征地农民和村委会的策略最终趋向于 均衡解 (顺从, 合规操作), 这样的博弯均衡结果更有 利于和谐社会的发展。

\section{4. 结论与展望}

征地冲突的复杂性制约了传统研究方法的效果, 函需探索能够更好解析冲突机理的方法。本文以集体 土地征收引起的利益冲突为研究对象, 一方面在有限 理性假设基础上建立了征地冲突中村委会群体与被征 地农民群体的演化博弯模型。另一方面, 采用多主体 


\section{Risk Analysis and Crisis Response in Big Data Era (RAC-16)}

建模工具 NetLogo 验证模型的演化稳定策略。仿真结 果表明，在实际工作中，可以通过对地方政府和被拆 迁人的收益进行动态调整以实现最有利于社会稳定发 展的策略。本文研究成果能够较好地为村委会合理、 合法、高效完成拆迁工作提供科学决策依据, 从理论 与方法上为构建和完善征地冲突预警和管控机制奠定 基础。

综合数值实验结果与分析表明, 策略组合 (被征地 农民顺从, 村委会合规操作) 是现实工作中最有利的博 亦均衡结果, 对完成集体土地征收, 推进城镇化以及 维持社会稳定均具有正向影响。基于演化博弯视角, 若要实现这一最有利的博弯均衡策略, 在实际工作中 主要有以下解决方案: 一是提高被征地农民顺从收益。 如充分保障被征地农民的合法权益, 实施顺从奖励政 策, 政府采取有效措施拓宽被征地农民就业途径, 解 决农民采取顺从策略的后顾之忧。二是降低村委会违 规操作收益。包括提高惩罚力度、加强违规操作监管, 设置合规操作奖励等提高合规操作收益, 有效引导违 规操作策略向合规操作策略转变。

受限于时间与研究目的, 本文的研究尚有一定的 不足, 如在村委会与被征地农民两个群体内部仅考虑 了采取两种策略的比例变化来体现内部的异质性, 没 有充分考虑两个群体内部的异质性; 在仿真研究时, 尚缺乏针对群体人数比例, 策略初始比等参数的敏感 性分析。未来的研究将克服这些不足, 以深化集体土 地征收的村内冲突分析。

\section{Acknowledgements}

This study was supported by National Natural Science Foundation of China (No.41171402) and (No. 71503228)

\section{致谢}

本研究得到了国家自然科学基金项目 (41371187)和 (71503228)的资助。

\section{参考文献}

[1]叶剑平, 马长发, 张庆红. 土地要素对中国经济 增长贡献分析. 财贸经济, 2011, (4) :111 - 117.

[2]Ding, C. Lichtenberg, E. Land and urban economic growth in China. Journal of Regional Science, 2011, (31): 299 - 317.

[3]Shen, L. Y. Peng, Y. Zhang, X. L. and Wu, Y. Z. An alternative model for evaluating sustainable urbanization. Cities, 2012, 29(1): 32-39.

[4]Wu, Y. Z. Peng, Y. Zhang, X. L. Skitmore, M. and
Song, Y. Development priority zoning (DPZ)-led scenario simulation for regional land use change: the case of Suichang County, China. Habitat International, 2012, 36(2): 268-277.

[5]谭荣, 曲福田. 市场与政府的边界: 土地非农化 治理结构的选择. 管理世界, 2009, (12): $39-48$.

[6]彭小兵. 城市拆迁冲突公共治理的文化价值视域. 重庆大学学报（社会科学版), 2011, (3): 30 - 38 .

[7]于建嵘. 土地问题已成为农民维权抗争的焦点一 一关于当前我国农村社会形势的一项专题调研. 调研世界, 2005, (3): 22 - 23.

[8]于建嵘. 我国农村集体土地所有权虚置成因. 伊 犁师范学院学报, 2001, 03:1-6.

[9]谭术鬼. 农民失地及其附属权利的丧失. 财经科 学, 2006, 01:88-92.

[10]谭术鬼, 涂姗. 征地冲突中利益相关者的博亦分 析-一以地方政府与失地农民为例. 中国土地科 学, 2009, 11:27-31+37.

[11]鲍海君. 拆迁危机的制度根源及其对策. 武汉大 学学报 (哲学社会科学版),2009,06:825-829.

[12] 柯小兵, 何高潮. 从三层博弯关系看土地征收 制度改革一一基于某大学城征地案例的分析. 中 国土地科学, 2006, 03:14-18.

[13] 李红波, 赵俊三. 征地制度改革动态博亦分析. 中国土地科学, 2010, 10:25-29+35.

[14] 谭术魁, 齐睿. 中国征地冲突博弯模型的构建 与分析. 中国土地科学, 2010, 03:25-29+59.

[15] 唐代中, 马卫锋. 基于演化博亦的城市拆迁补 偿机制研究. 财贸研究, 2007, 06:25-28+66.

[16] Tan, R. Qu, F. Heerink, N. Mettepenningen, E. Rural to urban land conversion in China-How large is the over-conversion and what are its welfare implications? . China Economic Review, 2011, (22): 474 - 484.

[17] 周飞舟. 生财有道: 土地开发和转让中的政府 和农民. 社会学研究, 2007, (1): 49-82.

[18] 盛昭瀚, 李静, 陈国华等.社会科学计算实验 基本教程. 上海三联书店, 2010.

[19] Zhao, H. Ding, H. Wang, H. Agent-based simulation of fish boats evacuation. Journal of Risk Analysis and Crisis Response, 2015, 5(3): 152-160. 